\title{
EBENE UND SPHÄRISCHE TRIGONOMETRIE
}

\author{
von \\ DR. PHIL. GERHAR D HESSENBER G \\ weil. ord. Prof. an der Technischen Hochschule Berlin
}

Funfte Auflege durchgenehen von

DR. H ELLMUTH KN ESER

o. Prof. an der Universitat Tahingen

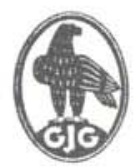

WALTER DE GRUYTER \& CO.

vormals G. J. Goschen'sche Verlagehandlung - J. Guttentag, Verlagsbuchbandlung - Georg Reimer - Karl J. Trabner - Veit \& Comp.

B E R L I N 1957 


\section{(C)}

Copyright 1957 by Walter de Gruyter \& Co. - Alle Rechte, elnschl. der Rechte der Herstellung von Photokoplen und Mikroftlmen, von der Verlagshandlung vorbehalten. - Archlv-Nr.110099. - Druck: Lindemann \& Lidecke, Berlin So 36. - Printed In Germany. 